\title{
Analysis of Materials for Heat Transport in Tokamaks
}

\author{
Márcio Belloni, Thadeu das Neves Conti \\ Institute of Energy and Nuclear Research, São Paulo, Brazil \\ Email: prof.belloni@gmail.com, tnconti@gmail.com
}

How to cite this paper: Belloni, M. and das Neves Conti, T. (2020) Analysis of Materials for Heat Transport in Tokamaks. World Journal of Nuclear Science and Technology, 10, 39-46. https://doi.org/10.4236/wjnst.2020.101005

Received: September 24, 2019

Accepted: December 16, 2019

Published: December 19, 2019

Copyright $\odot 2020$ by author(s) and Scientific Research Publishing Inc. This work is licensed under the Creative Commons Attribution International License (CC BY 4.0).

http://creativecommons.org/licenses/by/4.0/

c) (i) Open Access

\begin{abstract}
Every nuclear power reactor, whether of fusion or fission, is essentially a thermal system that generates electricity. In this sense, there are several problems in relation to this heat transport. The model of plasma confinement by magnetic force, in the nuclear fusion (sterellator and tokamak), has only been 20 years and recently some success in the quality of the generated plasma has been achieved. However, due to the large amount of energy coming from the plasma, the choice of the material that will carry the generated energy is quite troublesome, due to the need to handle a very high temperature for the nuclear fission standards. Solutions are explored by the scientific community to transport the energy generated in the case of the primary circuit, after exceeding breakeven temperature and models that are based on the fission reactors of the fourth generation and those currently in operation, to search for solutions regarding the transport of heat generated for the generation of electric energy. Several materials such as pressurized water, sodium, helium and boron have been considered and studied to form the primary heat transfer circuit for the exchanger. A thorough analysis of these materials is necessary. This research looked at some of these materials for heat transport and power generation. Lithium and helium were found to be the probable materials for conveying heat and cooling in the blanket. The results show that research on blanket materials needs more attention. The quality of these materials needs to be improved by material research, with the ODS EUROFER alloy and other research to reduce material erosion by helium nano bubbles. Plasma quality needs to be improved to keep constant and free of impurities when using lithium in liquid form.
\end{abstract}

\section{Keywords}

Thermonuclear Fusion, Tokamak, Renewable Energy, ITER Project, Material Analysis 


\section{Introduction}

In any system of electric power generation based on thermodynamics, it is used the transfer of thermal energy for its transformation into mechanical energy, basically to move turbines generating electric energy. Thus, in a hypothetical reactor of nuclear fusion, there is great difficulty in taking advantage of the heat generated.

\section{Objectives}

This study aims to analyze the best means of transport of the energy produced in tokamak type nuclear fusion reactor for the generation of renewable electric energy.

\section{Methodology}

The hypothetical-deductive method is presented. Bibliographic research was conducted to collect knowledge about controlled thermonuclear fusion and tokamak operation, as well as fourth generation reactors and those currently in operation. Visits were also made to the USP Institute of Physics (IFUSP) plasma studies laboratory to learn about the on-site tokamak and visits to the Energy and Nuclear Research Institute (IPEN/CNEN) to learn about the current model of nuclear fission and the perspectives on nuclear fusion. At these sites, questions were asked about the experimental tokamak and the IEA-R1 nuclear reactor to learn how core and plasma heat are mobilized.

\section{Development}

It is recognized that the basis of any study on tokamak nuclear fusion is supported by three fundamental pillars, namely, the study of the nuclear forces involved, the study of electromagnetism used for magnetic plasma containment, particle thermodynamics, hydrodynamics of the plasma [1].

The plasma state required for nuclear fusion, is by its nature an ionized gas. In this sense, the protons are free of their electrons so they have a very considerable repulsion force, forming a barrier of repulsion, and must be approximated enough that the hadronic force, offered by the gluons, renders hydrogen isotopes in a new element, that is, helium. To overcome this barrier, heat is supplied to the plasma by increasing the kinetic energy of the particles by changing the atomic mass of the isotopes. This is done by delivering thermal energy to the plasma [2].

The amount of heat generated poses a great challenge in the transportation of this heat, and at this moment it is necessary to pay attention to the related phenomena. Due to the fact that the plasma is vacuum-packed, the use of the generated heat avoids the convection caused by air, which would also disturb the integral of the plasma. On the other hand, this also decreases the value of the energy used, since with the vacuum, only the thermal radiation and the emission of neutrons can be considered. The conduction of heat does not occur because 
the conductive element is missing. But even with only elements of thermal radiation and fast neutrons, it is necessary to study in detail the element that is sufficiently resistant to the point of effecting the exchange of thermal energy with the plasma.

In the tokamaks, a structure is used that serves as moderator element and also captures the heat generated. This is the "blanket", which is created with material that absorbs the fast neutrons by performing several important roles in the fusion reactor. First, it reduces the speed of the neutrons and particles emitted in the fusion and also attenuates the generated heat, in order to protect the exterior of the reactor, also, avoiding that the plasma interferes in the generation of the created electromagnetic field, that must be in low temperature. In the case of ITER, electromagnets made from superconductors require temperatures in the order of $-269^{\circ} \mathrm{C}[3]$.

In the ITER project, as in Figure 1, the blanket system coats the inner surface of the vacuum chamber, and its main function is to provide shielding for the chamber and the superconducting magnets of the heat flux and the neutron flux, as the neutrons passing through this system are moderate, the kinetic energy of the neutrons is transformed into heat is transferred to the refrigerant for the purpose of generating electricity. The ITER blanket system is one of the most problematic along with the diverse system due to the fact that they will be the first contact of the radiation emitted by the hot plasma. Currently the material to be used in this system is beryllium due to its physical properties and possibly at a later stage a tritium regenerative blanket system will be tested [4].

In this way, one must choose the most suitable material for such capture of the thermal radiation. If on the one hand the material must be a good conductor of heat, it must also be sufficiently resistant to the radiation of the X-rays, high-speed neutrons and $a$ particles emitted in the fusion, thus avoiding to change the structure of the material [4].

It is possible to have an idea of the value of heat if you consider the system as ideal according to the theory of the blackbody and the monochromatic emissive

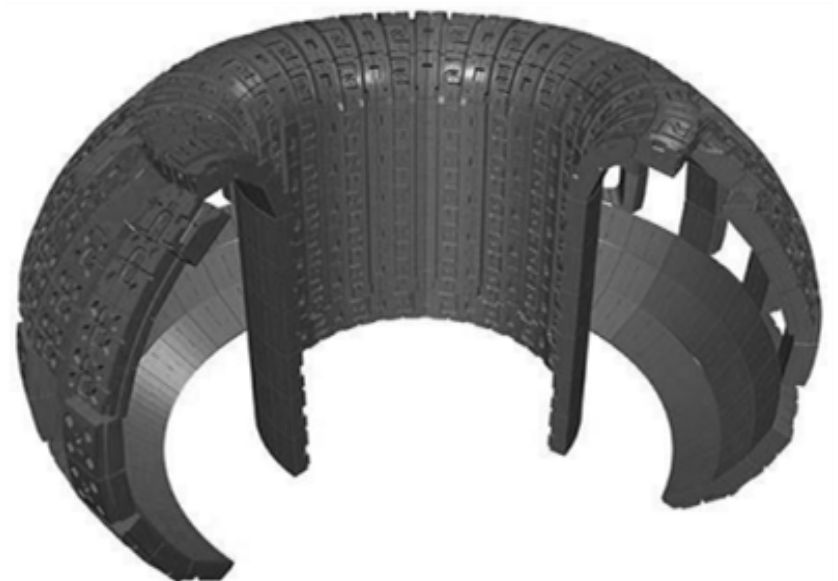

Figure 1. Blanket of the ITER tokamak. Source: CABRERA (2013). 
power. It is obtained by integrating the monochromatic emissive power over the entire wavelength range [5]. In this sense, the value of integration results in the mathematical model:

$$
E_{n}=\sigma \cdot T^{4}
$$

If the system behaves as a blackbody in which there is a state of equilibrium between particles and the radiation field, the flux of radiation from the surface is expressed by Stephan-Boltzmann's law [6].

$$
I=\propto \cdot T^{4}
$$

Analyzing the mathematical model proposed by Boltzman, one can reach the temperature value to overcome the repulsion barrier. One of the most latent problems of the fusion reaction is precisely its greatest advantage: the heat. A nuclear fusion reactor generates more than $10^{9} \mathrm{~K}$.

\section{Materials Used}

The temperature, in the tokamak, is captured by the "blanket" that has the condition of protecting the exterior systems of the containment vase. In the "blanket", channels where the refrigerant circulates, transport the generated heat to the secondary circuit, besides cooling the structure so that the emission of heat and radiation does not occur in the form of a particles, high speed neutrons and $\mathrm{x}$-rays for the external tokamak systems, such as electromagnets. This time, the material from which the "blanket" is made must be a little reactive and capable of decelerating neutrons, where beryllium, graphite or tungsten are recommended.

In the example of ITER, in Figure 2, the blanket covering a surface of $600 \mathrm{~m}^{2}$ is one of the most critical and technically challenging components. Along with the diverter, it directly faces the hot plasma.

Due to its unique physical properties (low plasma contamination, low retention

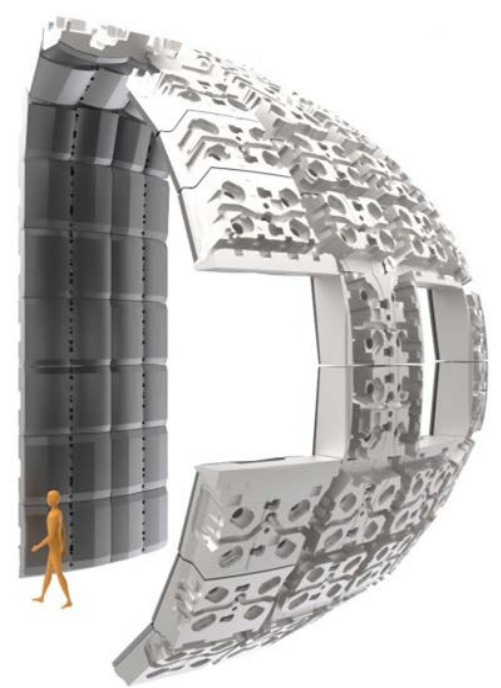

Figure 2. Blanket of the ITER. Source: ITER Organization. ITER Project web site. 
of fuel), beryllium was chosen as the element to cover the first wall in that case. The rest of the blanket modules will be made of copper and high strength stainless steel (EUROFER). ITER will be the first fusion device to operate with an actively cooled blanket, the cooling water will be injected at $4 \mathrm{MPa}$ and $70^{\circ} \mathrm{C}$ and will remove up to $736 \mathrm{MW}$ of thermal energy.

Although ITER will use water, which is pressurized, it can transport more energy without reaching the critical state [3]. But for a reactor with the power to generate electricity commercially and effectively, it is not the best option, even possessing the versatility of being abundant, cheap and easy to control. Its low boiling point avoids its use in high efficiency reactors.

Like the fast generation 4th generation reactors, sodium, which is already studied in several reactor projects of this generation, is a very interesting alternative. In this understanding, Wilma dos Santos Bastos explains that the use of sodium is a mature and dominated technology. Its use in the exchanger is very feasible, since it is already known the use of sodium in reactors of Japanese 4th generation with power of $1500 \mathrm{MW}$ (JSFR). One of its greatest advantages are:

1) high thermal conductivity $\left(68.8 \mathrm{~W} / \mathrm{m} \cdot \mathrm{K}\right.$ at $\left.450^{\circ} \mathrm{C}\right)$;

2) high temperature $\left(\approx 550^{\circ} \mathrm{C}\right)$;

3) Corrosion caused by sodium is easily controlled [7].

In the same comparative sense, it is possible to analyze the nuclear reactors of the type HTGR that can reach, in the refrigerant fluid, the temperature of $750^{\circ} \mathrm{C}$ to $1000^{\circ} \mathrm{C}$. In these reactors, a lot of the helium is used, because the same one is inert chemically, has a low neutron absorption shock section and has good properties with respect to heat transfer. The use of conventional coating materials, such as stainless steel, is not necessary [8].

However, many authors point to Lithium as the best option for transporting the generated energy. (US Nuclear Energy Policy Study Group, 1971, page 194). More precisely, its $\mathrm{Li}^{7}$ isotope [9]. This is justified because the melting and boiling point of lithium is higher than the other elements of group I, being of $181^{\circ} \mathrm{C}$ and Boiling is of $1347^{\circ} \mathrm{C}$. The bombardment of Lithium Isotope will generate Tritium $\left(\mathrm{H}^{3}\right)$. This explains the authors' preference. The atomic interactions between the ${ }^{7} \mathrm{Li}$ isotope and the fast neutrons produced by nuclear fusion make $\mathrm{Li}$ thium the best option for heat transport. In addition, the increase in pressure in the primary circuit may raise the boiling point of the lithium, causing it to carry a much larger amount of heat. The reaction with the lithium will generate the tritium that can be used by the own reactor since it will suffer the shock with fast neutrons. In the reactor, it will be produced locally by neutron bombardment (produced in the fusion reaction) of the fertile lithium layer [10]. Thus, they have the following reaction.

$$
{ }^{0} \mathrm{Li}+{ }^{1} \mathrm{n} \rightarrow{ }^{4} \mathrm{He}+{ }^{3} \mathrm{H} \quad[11]
$$

The model of regeneration of lithium and removal of the tritium generated, to serve as fuel in the plasma. Recovery of the tritium would be done by cooling the lithium to a temperature near its melting point, filtering the precipitated $\mathrm{Li} / \mathrm{T}$ 
and heating it to its decomposition temperature by a distillation or gas extraction process. However, problems to pump lithium by an extreme electromagnetic field are circumvented by several hypotheses but without a conclusion.

Several methods have been discussed to solve the problem of the great power needed to pump the lithium into a strong magnetic field. There is a possibility to coat the lithium-containing tubes with a nonconductive material, but pumps that move the fluidic lithium should pay special attention. Research shows that DC electromagnetic pumps have yielded great results in this case. These pumps have no moving parts and need no further maintenance.

Spitzer also mentions this possibility and suggests that such material should not be corrosive or brittle. The fact that the insulation material has to withstand corrosion by hot lithium and thermal stresses involves serious technical problems. He also studied the possibility of lithium remaining stagnant and the removal of blanket heat with water [12].

A model of nuclear fusion reactor, in Figure 3, demonstrates how to capture the heat generated. In this case, it is verified that the transport is effected by radiation, since the plasma makes impossible the conduction or convection [10].

In the case of fusion reactors, helium is the product of the reaction and can be collected and used in the cooling and energy transport system. The use of helium is supported by several researchers, including the fact that the projected commercial tokamak models use new material for their structure, ferrostic-martensitic hardened by dispersion of oxides and denominated (ODS EUROFER) for structural use. Thus, helium is indicated by its reaction with this alloy. It occurs that the helium has low susceptibility with respect to the ODS EUROFER alloy [13].

Big problem encountered is the corrosion caused by helium when in contact with metals. According to tests, helium, when in contact with metals, in nuclear reactions, form bubbles of nanometric size. These bubbles, when in large numbers, collide forming larger bubbles (in order of micrometer), causing the destruction

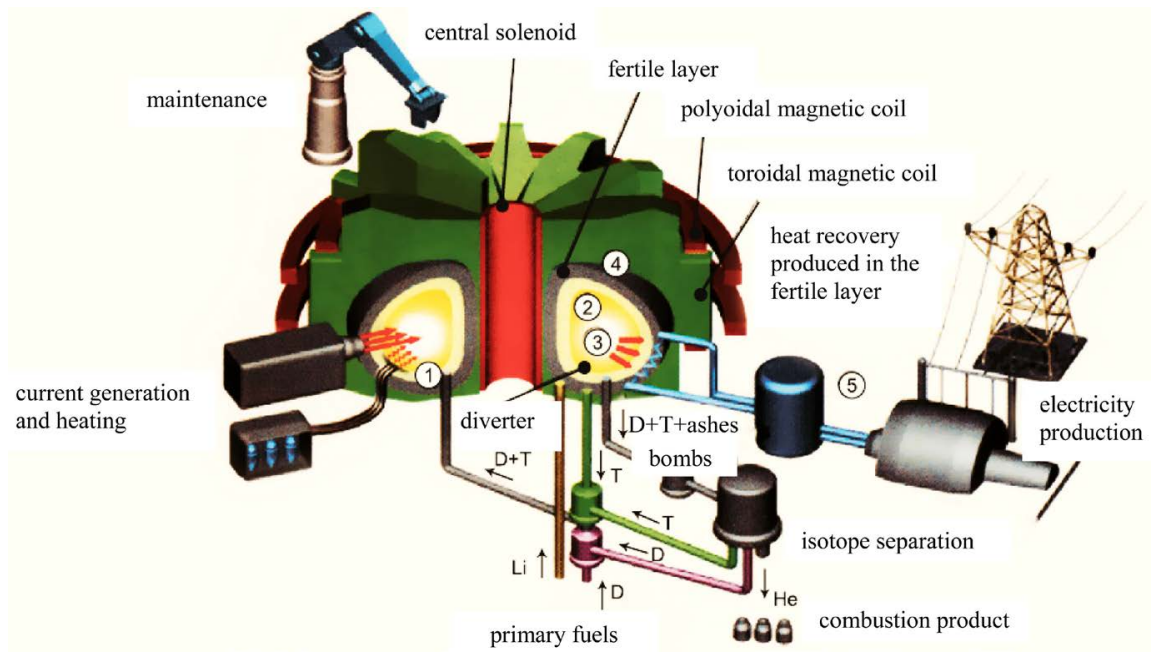

Figure 3. Nuclear fusion reactor model and the lithium blanket. Source: Manso and Varandas, 2009, p. 71. 
of the material. It has been found that multilayer copper and niobium composites have caused capillaries formed by deposited helium and not bubbles.

These capillaries will act as channels through which helium can escape, without damaging the structure. Thus, structural integrity will be maintained, and there will be a slight leakage of the helium contained in the material, a priori.

\section{Conclusions}

Tokamak is observed to be the most likely reactor for generating electricity efficiently. Especially with the ITER project, controlled thermonuclear fusion for power generation is getting closer and closer to reality. There is also a possibility to use various generated coolants and heat absorbers, including pressurized water, lithium, helium and sodium.

This time, we should look at existing technology, both in what is already used in the operation of reactors such as Angra 1 and 2, as well as the fact that it has a lot of risk and accident documentation, as in new projects like advanced nuclear reactors. Fourth generation reactors provide much of the material already questioned in the new nuclear refrigerants, although it was never a reactor that supplied as much energy as a large fusion reactor like the ITER project. To proximity to the hot plasma the better material is the lithium in liquid state and the helium because the actual material studs and the physicochemical features. Lithium is an option for heat transport because its physicochemical features are very interesting for the system. In the liquid state, it is easier to contain lithium in the primary circuit and changer, but lithium cooling should be avoided to prevent fluid loss (LOCA) even in case of plasma cooling. Very easily, according to the tests observed in the existing experimental tokamaks. Thus, with regard to lithium, studies on plasma maintenance are required to be constant and homogeneous, respecting Lawson's law.

In addition, as it is already used in fission reactor designs and is the product of hydrogen fusion of nuclear isotopes, helium is seen as an elegant and effective solution for transporting the heat generated in nuclear fusion. The corrosion problem observed in the literature, where helium lodges in metals such as nanofilled bubbles, causing its destruction, is being addressed in studies of innovative alloys such as ODS EUROFER and techniques for the use of niobium and multilayer copper metals. Helium circulation channels facilitate even the separation of other gases. The choice is then to use helium and lithium for their physicochemical characteristics and the research so far pointed out.

\section{Conflicts of Interest}

The authors declare no conflicts of interest regarding the publication of this paper.

\section{References}

[1] Belloni, M. (2017) Sub-Atomic Particles for Effectiveness in Controlled Thermonuclear Fusion Reactions. Proceedings of the 24th International Symposium on 
Scientific and Technological Initiation of USP, Sao Paulo.

[2] Belloni, M. (2017) The Thermonuclear Fusion Process the Thermonuclear Fusion Process. Proceedings of the Week of Science and Technology, Guarulhos.

[3] ITER Organization. The International ITER Project for Fusion: Why? Website of the ITER Project. Electronic Document. https://www.iter.org

[4] Cabrera, C.E.V. (2013) Neutron Evaluation of the Insertion of a Transmuting Layer into a Tokamak System. Dissertation (Master's Degree), UFMG, Minas Gerais.

[5] Schimidt, F.W., Hendereson, R.E. and Wolgemuth, C.H. (1996) Introduction to Thermal Sciences: Thermodynamics, Fluid Mechanics and Heat Transfer. Ed Blucher, São Paulo.

[6] Tomimura, A. (1980) Controlled Thermonuclear Fusion. Nuclear Energy. Military Engineering Institute, Ministry of the Army, Rio de Janeiro.

[7] Bastos, W.S. An Introduction to IV Generation Rapid Reactors. http://www.ipen.br

[8] Terremoto, L.A.A. (2004) Fundamentals of Nuclear Reactors Technology. http://www.social.stoa.usp.br

[9] Ribeiro, G.F. Diagnosisoflithium; Braziliansituation. CNEN, Rio de Janeiro. http://www.iaea.org

[10] Manso, M.E. and Varandas, C.A.F. (2009) Nuclear Fusion, an Energetic Option for the Future. Physics Gazette, Vol. 29, Lisbon.

[11] Coelho, P. (2013) Hydrogen Isotopes: Deuterium and Tritium. http://www.engquimicasantossp.com.br

[12] Carvalho, S.H. (1980) Blanket for Fusion Reactors: Materials and Neutron. Master Degree Dissertation, Federal University of Rio de Janeiro, Rio de Janeiro.

[13] Zimmermann, A.J.O., Sandim, H.R.Z. and Padilha, A.F. (2010) The New EUROFER Stainless Steels Used in Nuclear Fusion. Rem Revista Escola de Minas, 63, 287-292. https://doi.org/10.1590/S0370-44672010000200012 